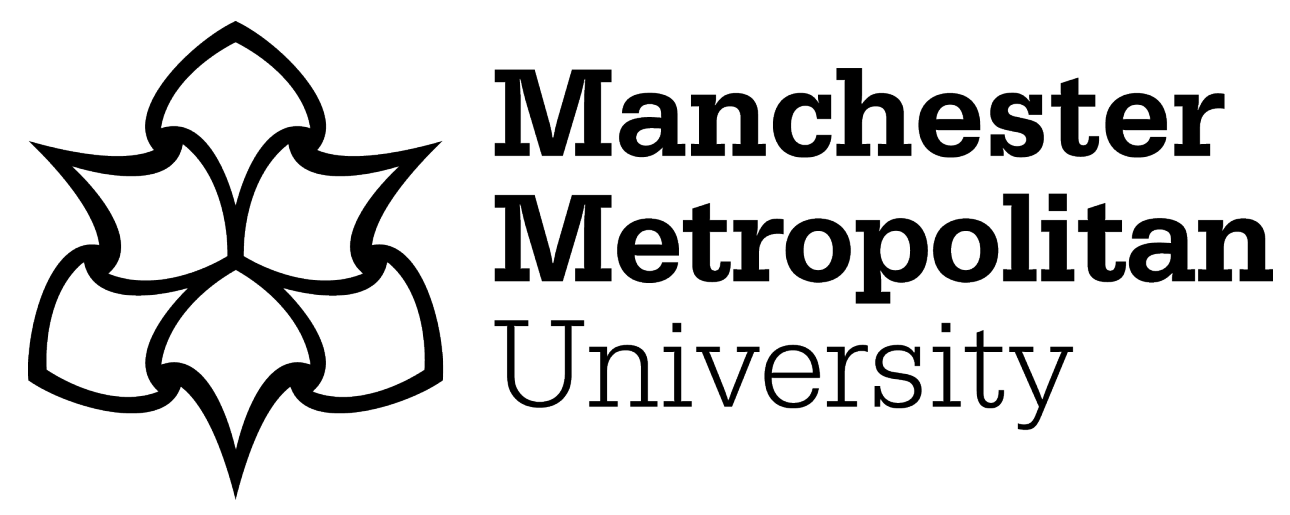

Webb, P Taylor, Sellar, Sam ORCID logoORCID: https://orcid.org/00000002-2840-5021 and Gulson, Kalervo N (2020) Anticipating education: governing habits, memories and policy-futures. Learning, Media and Technology, 45 (3). pp. 284-297. ISSN 1743-9884

Downloaded from: https://e-space.mmu.ac.uk/624181/

Version: Accepted Version

Publisher: Taylor \& Francis

DOI: https://doi.org/10.1080/17439884.2020.1686015

Please cite the published version 


\title{
Anticipating education: Governing habits, memories and policy-futures
}

\author{
P. Taylor Webb \\ Associate Professor \\ University of British Columbia \\ Department of Educational Studies \\ Faculty of Education \\ Vancouver Campus \\ Ponderosa Commons North (Oak House) \\ 6445 University Boulevard \\ Vancouver, BC Canada V6T 1Z2 \\ taylor.webb@ubc.ca \\ Sam Sellar \\ Reader in Education Studies \\ Manchester Metropolitan University \\ 1.43 Brooks Building \\ Manchester, M15 6BH \\ s.sellar@mmu.ac.uk \\ Kalervo N. Gulson \\ Professor \\ University of New South Wales \\ UNSW Arts \& Social Sciences \\ Morven Brown Building \\ UNSW Sydney, NSW 2052 \\ Australia \\ k.gulson@unsw.edu.au
}

Keywords: Education policy, anticipatory governance, artificial intelligence, time, temporality

To be published in Learning, Media and Technology 2020

This research was supported by the Social Sciences and Humanities Research Council of Canada. 


\section{Anticipating Education: Governing Habits, Memories, and Futures}

To speak of the subject now is to speak of duration, custom, habit, and anticipation. Anticipation is habit, and habit is anticipation: these two determinations - the thrust of the past and the élan toward the future - are ... the two aspects of the same fundamental dynamism. ... Habit is the constitutive root of the subject, and the subject ... is the synthesis of time - the synthesis of the present and the past in light of the future.

- Deleuze, 1991: 92-93

The use of data to govern education is increasingly supported by the use of knowledge-based technologies, including algorithms, artificial intelligence (AI), and tracking technologies (Fenwick, et al., 2014). ${ }^{1}$ New forms of datafication and automation enable governments and other powerful stakeholders to draw from the past to construct images of educational futures in order to steer the present (Hartong, 2019). This paper examines the competing conceptions of time and temporality that AI posits for policy and practice when used to anticipate educational futures. We argue that most educational futures are already delineated, and machinic expressions of time are the chronologies, habits, and memories that the educated subject inhabits rather than produces. If resetting educational habits and memories can be an alternative to algorithmic anticipations of education then we believe, paradoxically, that machines may help to reset them by accelerating them.

\section{Introduction}

Patton, et al. (2016) described policy practices that construct images of possible futures as either 'predictive policy' or 'prescriptive policy', where the former "refers to the projection of future states resulting from adopting particular alternatives" and the latter "refers to analysis that recommends actions because they will bring about a particular result" (p. 23). For instance, Beijing, Brazil, Canada, the

\footnotetext{
${ }^{1}$ We use the following definitions throughout: artificial intelligence is defined as the theory and development of computer systems that interact and perform human cognitive tasks (e.g., visual perception and speech recognition); and the following two features which can be discrete from, but are increasingly seen as aspects of AI, (a) algorithm is a defined list of steps for solving a problem and a computer program can be viewed as an elaborate algorithm; (b) machine learning occurs when computer systems learn from data, enabling them to make increasingly better predictions (Luckin et al., 2016).
} 
European Commission, Germany, Japan, OECD, and the UK have all developed offices with mandates to anticipate futures through different predictive and prescriptive policy initiatives (Wilsdon, 2014). Activities that these offices might engage in include: crowdsourcing maps for natural disasters, forecasting battlefield casualties, anticipating terrorism, and predicting gang-related crimes, or 'predictive policing'. Governing educational futures has been described as anticipatory governance (Selwyn, 2018; Williamson, 2016).

Within classrooms, Williamson (2016a) described the ensemble of different knowledge-based technologies as "a hybrid of data scientific practices drawing from statistics, computer science, information science, and machine learning, combined with expertise in psychology and neuroscience from the existing field of the "learning sciences"” (p. 401). Sensor technologies worn by students are an example of how knowledge-based technologies and AI are used in education practice (de Freitas, 2018). Sensors provide biometric and neurologic data, and these data are then used to design 'precision' pedagogies to anticipate future learning, perhaps even as an 'individualized' or 'personalised' future (Thompson \& Cook, 2017).

The classroom is not the only space where education futures are governed. Algorithms and machine learning are used to develop education policy recommendations, including 'real-time' measurements of system performances (i.e., school and university systems). Luckin et al. (2016) tied together data-driven aspects of education, and argued that: "[t]hrough the implementation of common data standards and data sharing requirements, [machine learning] will be able to provide analysis about teaching and learning at every level, whether that is a particular subject, class, college, district, or country" (p. 48). Consequently, Luckin et al. (2016) asserted that advances in AI will provide capabilities to diagnose, analyze, and intervene in school systems, in "real-time". They stated that AI "could produce the school-level data analysis that will indicate in real-time when a school is 
experiencing problems. ... Education systems will need to be nimble to take advantage of the rich realtime systems level analysis that will be continuously available (p. 48, our emphases).

These developments in AI and machine learning provide important context to our discussion, but our paper does not focus on specific technologies. Instead, we discuss the introduction of AI in education policy contexts to examine how time and temporality are used and inflected when anticipating educational futures with knowledge-based technologies. As such, we ask two main questions: Who or what conceives of temporality when anticipating educational futures? And how are time and temporality used surreptitiously, or in ways that are assumed and unacknowledged, when anticipating educational futures? For instance, readers might query what is 'real-time', or for that matter, 'rich real-time', given that humans and machines sense temporality differently (Parisi, 2013)?

This article is theoretical and speculative. It is connected to three bodies of literature: education governance and time (Thompson \& Lingard, 2017); AI in education (Fenwick, et al., 2014), and machinic reasoning of time (Parisi, 2013). We discuss how AI inflects anticipatory priorities in education (i.e., 'the future', grade placement, reading levels, employment opportunities) and how education systems anticipate what AI can do with extant data sets (e.g., student learning data, system performance data). The paper focusses on the ways educational subjects inflect competing conceptions of time, in which AI "would not add new qualities; on the contrary, it would subtract real time from lived experience" (Parisi, 2013, p. 240). Our thesis is that anticipatory governance abducts subjects in specific habits; governs subjects through provided memories; and (dis)orients subjects for calculable futures. Thus, the paper addresses the call of this special issue, literally, by outlining educational futures within competing conceptions of temporality. 


\section{Untimely Politics}

The "politics of temporality" (Adams et al., 2009, p. 247) produced by anticipatory governance revolves around two axes: how time is 'used' or practiced (by whom or what) in governance attempts (e.g., as a variable in different algorithms; as a social or cultural 'imaginary,' etc.), and how time is conceived. This suggests that in order to understand anticipatory governance in education it is necessary to understand time and temporality broadly. For the remainder of our discussion, time and temporality are understood in the following three modalities:

- Chronologic: practices involved with measuring time in regular divisions (e.g., past, present, future), to specify a fixed order of events. Chronological time is quantitative and empirical;

- Aionic: in contrast to chronologies; immeasurable, durational, 'eternal', circular, unbounded, 'timelessness', 'slo-motion'. Time is qualitative, intuited, sensed or prehended; "lived time” (Bergson, 2001);

- Kaironic: moments in which to act, moments of potential, "creative advance" (Whitehead, 1978), novelty, timeliness (e.g., 'right time', 'wrong time'), 'untimely', as a direct intervention into chronological orderings (Brown, 2005).

We discuss each of these temporal modalities further in the paper, and in relation to anticipatory governance practices in education.

Understanding the anticipation of education also requires understanding who or what is conceiving time. We are interested in how machines reason temporally and participate in a context characterized by "multiple experts of the future" (Rose and Abi-Rached, 2013). Rose and Abi-Rached (2013) explained,

Today we are surrounded by multiple experts of the future, utilizing a range of technologies of anticipation - horizon scanning, foresight, scenario planning, cost-benefit analyses, and many more - that imagine those possible futures in different ways, seeking to bring some aspects 
about and to avoid others. ... In the face of such futures, authorities have now the obligation, not merely to 'govern the present' but to 'govern the future.' (p. 14)

We want to stress that conceptions of time are generated by both policy makers and machines, in which "algorithmic rules now generate or construct patterns from the re-assemblage of data" (Parisi, 2019, p.

2). What is significant about machinic temporalities is the extensive range of applications produced by the intensification of new computing power and availability of (big) education data, including the possibility of AI to apprehend education data on 'their' own. This is to take seriously what others have described as an "autopoiesis" of machinic temporality (Stendera, 2015) and the many ways AI engages in temporal reasoning (Parisi, 2013).

Throughout our discussion, we use the example of learning analytics platforms (LAPs) as a way to illustrate some of the temporal implications involved with anticipating educational futures. LAPs have become a prevalent knowledge-based technology in education and are "programmed with the capacity to anticipate or predict pupils' probable future progress" (Williamson, 2016b, p. 136). Williamson (2016b) characterized learning analytics platforms as ways to use student learning data to track, anticipate, and predict future academic progress. We discuss and illustrate LAPs later in the paper, and in relation to educational futures specifically.

\section{Paper organization}

We begin by discussing approaches to AI that produce chronological anticipations of educational futures by analysing past experiences. Chrono-logics retain a privileged conception of time that has animated education governance since the 1950s. Chronological anticipations of educational futures are the product of machinic calculations and deductions of chronologic time. In this section we discuss the emergence of LAPs in education, and argue that chronological anticipations of educational futures 
concretize policy practices that financialize, privatize, and develop human capital (Brown, 2015).

Today, anticipatory governance automates and accelerates the development of human capital.

Next, we illustrate how educational futures also reside in aionic time. Aionic time is a wholly different conception of temporality, and one that contrasts with chronological conceptions. We dedicate substantial space to discussing Gilles Deleuze's (1994) unorthodox ideas of aionic time. We examine how educational subjects are positioned within colliding forms of governance when policy-makers and AI use different conceptions of time to anticipate educational futures. More importantly, we argue that machinic anticipations of educational futures govern the habits and memories of the educated subject, or what Parisi and Goodman (2011) describe as "mnemonic control".

The paper concludes within a third conception of time (kairos) to speculate about what might be done at this critical juncture for education policy and practice. If AI increasingly governs human capital development and its deleterious outcomes for particular groups, then what possibilities do we have to intervene in anticipatory practices? We conclude with some 'untimely' speculations, following Brown's (2005) claim that "[u]ntimeliness deployed as an effective intellectual and political strategy, far from being a gesture of indifference to time, is a bid to reset time" (p. 4). Like Deleuze (1994), we posit that one way to reset time is to reset temporal habits and memories. Moreover, and in contrast to governmental and other private attempts to control AI (e.g., checklists on 'ethics and trustworthiness in AI'), we argue that AI and machine learning can contribute to deterritorializations of educational habit and memory.

\section{Yesterday, Today, and Tomorrow: Chronological Anticipations of Education}

The dominant form of time in education is chronological, or serial arrangements of pasts, presents, and futures. The linear and teleological formations of chronologies are the precise analogues to forms of education governance that can be quantified and measured (Fenwick et al., 2014). In this sense of time, 
temporality is "frequently reduced to clocktime, economy is reduced to money matters and isotropic and decontextualized spaces dominate over meaningful places" (Rämö, 1999, p. 323, as cited in Papastephanou, 2014, p. 170).

Chrono-logics underpin the rationalities of the 'policy sciences' developed in the 1950s (Lerner \& Lasswell, 1951). The term 'policy sciences' referred to the role public policy could play in assisting governments to solve problems, including post war reconstruction and governing the state (i.e., employment, security, equality) (Simons, et al., 2009). The policy sciences were designed to provide solutions to social problems, and to "manage the 'public' and its problems" (Parsons, 1995, p. 6) through a multi-disciplinary approach that figured exclusively within the social sciences and included several perspectives: politics, law, sociology, economics, education, etc.

Chrono-logics assume that time is empirical, objective and something that can be counted (i.e., clocktime). Calendars, schedules, deadlines, and performance goals are the objects and practices of chronological education. For instance, chronological time can be manipulated through these objects and practices. What is interesting within chrono-logic politics is how time in education policy making is prestructured, and those in powerful positions are able to use time to their advantage (e.g., when meetings are scheduled; how determinations of who is 'late to class' are managed). Chrono-logics govern education endlessly as chrono-logics have a near hegemony on how temporality is conceived and practiced.

\section{Clocks and machinic time: Data infrastructures in education}

Marx (1863) argued that "[t]he clock is the first automatic machine applied to practical purposes.

The whole theory of the production of regular motion was developed through it" (np.). Today, the ascendance of $\mathrm{AI}$ is shaping new kinds of automatic machines that are used to govern education temporalities. For example, Selwyn (2015, p. 72) argued that 
algorithmically driven 'systems thinking' - where complex (and unsolvable) social problems associated with education can be seen as complex (but solvable) statistical problems. ... leads to a recursive state where data analysis begins to produce educational settings, as much as educational settings producing data.

Anticipatory forms of chronological governance reside within broad ideas of 'computational policy' that utilize AI to produce computational representations, modelling, simulations and related procedures (Gulson and Webb, 2017a). The integration of novel forms of data and the creation of new data platforms, in addition to the infusion of business principles into educational governance networks, produce intensified interactions between people, networks, algorithms and computational capacities.

Williamson (2016b) examined learning analytic platforms (LAPs) as one type of data platform in education, and one that focusses exclusively on educational subjects (i.e., students). Williamson (2016b) observed,

Learning analytics platforms act as anticipatory devices that are embedded within the pedagogic routines of the classroom, and are based on technical developments in 'machine learning'. The importance of machine learning algorithms is that they exhibit some tendencies of emergence, adaptivity, anticipation and prediction. Machine learning and predictive analytics software are part of a world in which 'probabilistic outcomes' and predictions about the future now prevail, with significant implications for how individuals think about and anticipate their own futures .... (p. 136)

It is important to note how data infrastructures, like LAPs, function to support and produce as particular forms of anticipatory policy in education. The primary application of LAPs is to identify students 'atrisk' and intervene computationally in ways that ameliorate deleterious learning outcomes (e.g., prevent attrition, increase matriculation, etc.) (West et al., 2016). Drawing on a broad range of fields, including 
the 'learning sciences', information theory, psychology, and computer science, LAPs attempt to deal with the complexity of human learning by analysing large educational data sets, including data from student forum interactions, access to resources such as libraries, and assessment outcomes. While LAPs do not depend on AI, the use of machine learning has identified "time effects", the unexplained increases or decreases in variable values, in predictions of student attrition (Aulck et al, 2016, p. 19).

Machine learning is able to calculate or compute chronologic time when constructing or modelling probable futures. In the context of LAPs, these calculations operate on three interrelated conditions or premises: 1) a naïve realist codification of learning (Scott, 2005); 2) algorithms that use these codifications for predictive purposes; and, 3) the generation of multiple simulations where users are able to undertake forms of self-assessment (Gibson, \& de Freitas, 2016). LAPs may be able to provide synchronous diagnoses and interventions (i.e., simulations), which model multiple temporal trajectories in order to anticipate student futures. LAPs, therefore, are premised on and produce forms of anticipatory governance through chronological computations of serial arrangements of pasts, presents, and futures.

There is wild variety in the development and usage of LAPs and other global data infrastructures in education, emerging over the past thirty years (Gulson and Sellar, 2018). These data infrastructures accelerate the "synchronization of educational cultures" through the insistence that time remains linear, teleological, and quantifiable (Papastephanou, 2014, p. 169, our emphasis). Chrono-logics assume time as a universal that confers sameness and homogeneity across lived and embodied experience (Bennett \& Burke, 2018). For example, LAPs depend on particular codifications (i.e., mathematical representations and reductions) to simulate learning, but in so doing, inevitably reduce, flatten, or hypostatize learning into computable, and for our purposes, representative categories (e.g., gender, age, ethnicity, etc.). That is, the learning simulations produced by LAPs can only compute what is codified, leaving very little 
outside of this representation and ensuing calculation. The predictions and anticipations of LAPs require computable variables, which are the 'chronically' arranged orderings of a student's past.

Chronological anticipations, then, flatten and reduce the number of educational futures. These futures are already largely determined and, in education, are frequently shaped by desires to financialize, privatize, and develop "human capital" (Becker, 1964; Brown, 2015; Foucault, 2008). Anticipatory education does not lie outside of the registers and practices of human capital development, but rather, automates and accelerates the chrono-logics that have transmogrified education into human capital development for the past sixty years. Moreover, futural human capital (i.e., future and anticipating human capital) will likely reproduce existing biopolitical inequities in education (Gulson and Webb, 2017b). Today, a 'computational biopolitics' that utilises information, code, and biology could easily automate and accelerate existing practices of sorting, tracking, mitigation, and optimization of gender, race, and sexualities associated with human capital development (Foucault, 2008; Rose, 2001).

\section{Summary}

The synchronization of global data infrastructures in education is redolent of 'control societies' that modulate the education and training experiences of human capital (Deleuze, 1992). The educated subject is no longer an 'individual' with an assumed 'potential' waiting to be unlocked through schooling. Rather, "[i]ndividuals have become "dividuals," and masses, samples, data, markets, or “banks." (Deleuze, 1992, p. 5). Educational subjects are constantly modulated as a "becoming-statistic" (race, gender, biometric, neurologic, etc.) (Sellar and Thompson, 2106).

Desire is what marks control societies "because they express those social forms capable of generating them and using them" (Deleuze, 1992, p. 6). For example, Stiegler (2016) argued that governance is now a form of "hyper control" through "self-produced personal data, collected by and published by people themselves - whether knowingly or otherwise - and this data is then exploited by 
applying intensive computing to these massive data sets" (p. 58). LAPs are not simple repositories of educational measurement, but platforms that produce desiring subjects. In other words, these platforms generate “"prosumers' of educational data - not just consumers of its archive, but also producers who interact with the data co-creatively" (Williamson, 2016b, p. 125). Anticipatory futures, then, are the extensions of chronologically arranged pasts and presents, and also ways to steer or nudge educated subjects to participate, anticipate, desire, and 'prosume' (rather than consume) their own chronologically arranged future. The educational subject and school system are now synchronized in the 'capitalist axiomatic' of human capital development (Deleuze \& Guattari, 1983, p. 184).

Anticipatory governance is the logical outcome of the chronological and quantitative epistemologies that education policy promulgates. The capacities of AI now accelerate the chronological epistemologies that have been used to govern education since the 1950s (Webb and Gulson, 2015). The preponderance of chronological anticipations obfuscates how the habits and memories of the educated subject are also governed. In other words, chrono-logics obfuscate how AI infers futures through its own sense of temporality developed from its own, non-human algorithmic learning. ${ }^{2}$ Aionic conceptions of time remain relegated to philosophical discourse and have been rarely discussed within the processes and practices of education policy (C.f., Thompson \& Cook, 2014; 2017). Nevertheless, aionic ideas of time provide additional ways to understand how AI calculates educational futures, perhaps providing one way to explain the endless cycles of human capital development in education. Again, we suggest that 'resetting time' can be a kaironic alternative to algorithmic anticipations calculated in chronological forms of educational governance.

\section{Aionic Anticipations of Education: Habits, Memories, and Futures}

In our time, as never before, the continuity from past to future is broken.

\footnotetext{
${ }^{2}$ Parisi (2019) discussed machinic thinking as “...automation of automation: the automated generation of new algorithmic rules..." (p. 2).
} 
- Rabinow, 2008, p. 59

Aionic conceptions of time stress the quality of duration (e.g., 'eternal', endless, cyclical) and differ from chronological conceptions of time that stress sequencing of events and binary teleologies that extend backwards or forwards (e.g., past and future). Aionic time is neither successive nor serial, but instead, intensive or affective, repetitive and non-representational (Deleuze, 1994). Aionic time is something sensed and prehended, and "stretches eternally in two directions (past and present) at once" (Piotrowski, 2019). If chronos presupposes quantitative epistemologies, aion presupposes qualitative sensibilities. $^{3}$

Deleuze (1994) developed a theory of aionic time in relation to what he called the three syntheses of habit, memory, and novelty. This non-chronological conception of time was developed "in contrast to views where time acts as a container for events, or where time is a representation according to which events are situated" (Williams, 2011, p. 62). Experiences of time are intensive and orient subjects through various sensations and prehensions of time. Hence, time is contextual - not neutral nor objective - and operates relationally as a "dynamics of power and inequality" (Bennett \& Burke, 2018, p. 3). Deleuze (1994) believed that one way to reset time was to reset habits and memories.

Deleuze's conception of aionic time rests on his idea of 'synthesis' and, specifically, his ideas of 'passive' and 'active' syntheses. Active syntheses are concerned with conscious thought and passive syntheses are produced non-consciously, through sensation and prehension. Non-conscious cognition has also been a way to describe the abductive epistemologies of AI (Hayles, 2014), including capacities to infer time and reason temporally (Parisi, 2013). ${ }^{4}$ While his ideas of aionic time are some of the most

\footnotetext{
${ }^{3}$ Epistemology privileges ideas of discursive 'knowledge', which is not a good metaphor for understanding duration. Embodied sensibilities may, instead, be an alternative way to understand duration.

${ }^{4}$ Non-conscious cognition is a way to describe 'thought' unique to AI, and it has nothing to do with human intelligence or with regard to it being or serving as a replicant of human intelligence. The characterization of nonconscious cognition is attributed to forms of AI engaged in 'unsupervised learning', rather than forms of AI that use training data in 'supervised learning'.
} 
developed, Deleuze's 'three syntheses of time' can be unintuitive, particularly his emphases on the ways habits and memories intuit, sense, and prehend temporality.

\section{First synthesis of time}

Deleuze (1994) argued that the first synthesis of aionic time is habit. Habits are a collection of passive, unconscious processes of sensation and prehension. The colloquialism of one's 'internal clock' is a way to describe these habits; whereas, 'jet-lag' is symptomatic of upsetting temporal habits (i.e., chronobiology, metabolic rates, circadian rhythms, heartbeats, sleep cycles). Sensation and prehension are interdependent processes and operate on the basis of passive encounters rather than conscious recognition. They are habitual, instinctual and related to a range of passive senses interacting with environments that are constantly in flux (e.g., imperceptible increases and decreases of daylight). For Deleuze (1994), sensations and prehensions operate as multiplicities. We passively encounter - and not recognize - a number of different sensations and prehensions. It is through these automated and habitual syntheses that time and temporality are folded subjectively, and what we have discussed as affective and embodied sensibilities when interacting with education policy (Webb and Gulson, 2012; 2013).

In relation to anticipating education, Thompson and Cook (2014) borrow Deleuze's (1994) idea of 'habit' to argue that "the habit of education policy-making ... is the collective contraction of past events into a lived present that is future oriented", wherein, education policy-making "contracts past events or problems into a solution-focused lived present as a means to build a better future" (p. 706). Thompson and Cook (2014) observed that education policy-making is habitual "because the temporalities to which policy-making activities give rise have not changed, the thinking is trapped in old temporal circuits" (p. 706). We agree that educational governance is trapped within habits of chronological time. Hence, anticipations of education circulate and repeat staid habits of both educational practices and temporalities, often under the pretense of 'the future'. 
Durational ideas of time help explain how anticipatory governance automates and accelerates forms of continuous control evidenced as "perpetual training" (Deleuze, 1992, p. 7). For example, ideas of waiting and boredom - correlates to anticipation - enact affective investments of educational futures. The durational and repeating subject characterized as the 'bored student' is not intrinsically unmotivated or unimaginative, but trapped in the habitual practices and memories of schooling. Boredom, then, is “...experienced as a painful suspension of the passage of developmental time" (Bignall, 2010, p. 8). Boredom also highlights that the technologies of anticipation produce inevitable moments of waiting and duration (Piotrowski, 2019). Boredom and waiting are used as an administrative tactics of "limitless postponements" in education (Deleuze, 1992, p. 5). In other words, the time spent anticipating educational futures is accompanied by waiting and boredom - a "cruel optimism" (Berlant, 2011) built into some educational anticipations. The wait-times embedded in machinic anticipations automate and synchronize desires to become promised forms of human capital (Brown, 2015), but these futures will not eventuate for many (Sellar and Zipin, 2019). Anticipatory governance is never as dystopic as when it accelerates the past in painfully suspended automated presents.

As such, the anticipating subject is also the accretion of all the tiny moments of waiting and boredom that accompany promises of educational futures. Bignall (2010) argued that boredom actually "aids the fulfilment of desire" (Spacks, 1995, as quoted in Bignall, 2010, p. 8), where "[b]oredom is not simply disabling and disruptive, but is also understood as the putative ground for the emergence of reflexive selfhood" and plays a "provocative role ... as a causal or motivating force of constructive processes" (Bignall, 2010, p. 8). In other words, anticipatory wait-times and educational boredom are productive because they press upon educational subjects to accelerate the embedded wait-times of anticipation. These productive processes of selfhood might arise from efforts to end the habitual 
boredom of schooling. For example, the productive processes of selfhood might be desires to enact LAP profiles in order to accelerate and potentially deterritorialize the habitual routines of curriculum.

\section{Second synthesis of time}

The second synthesis of aionic time is memory. Memory organizes habits like photographs that assist (or trigger) the passive syntheses of recollection, and like the passive motor-memory of muscle, for example, when playing the piano. However, memory is not only embodied, but organizes habits along a principle of duration, "without which the present would never pass" (Smith, 2013, np). Memory ostensibly functions to explain how habits come to operate and, in Deleuze's formulation, contrasts with psychological renderings of habit.

Memory was used by Deleuze (1994) to illustrate how chronological time is paradoxical. Smith $(2013, \mathrm{np})$ described the predicament of memory, or what he described as "the paradox of contemporaneity", when he observed the following,

[a]lthough we tend to think that the present 'is' and the past 'is not' or 'is no longer,' the opposite is in fact the case. No matter how small it may be, it is the passing instant that 'is not' (since whenever we try to grasp it, it has passed on and been replaced by the succeeding instant), whereas the past itself is preserved.

Chronological ideas of the present become problematic once time is understood as durational, 'eternal', or endless. In other words, chronology is not the container of educational events, but rather, duration provides the grounds for chronological explanations of time. Memory, then, is the predominant way to govern educational habits. In other words, memory orients educational subjects to the durational qualities of time and "colonizes" educational subjectivities through memory while obfuscating and erasing possible futures not "coordinated and created by the present and past" (Thompson \& Cook, 2014, p. 707). 
Returning to our example, LAPs can be conceived as an archive of codified educational memories (in addition to serving as simulations derived from chronologically arranged student data to track and anticipate future academic progress). LAPs represent, memorialize, and archive discrete learning moments (as 'data'). As such, anticipatory simulations both produce and delimit educational futures by memorializing discrete (and likely fleeting) learning moments. Parisi and Goodman (2011) describe this form of governance as "mnemonic control", through which unconscious habits of time are exploited within codified learning memories required for calculable chronologies. The hypostatizing of lived experience omits or excludes aspects of learning not codified, and mnemonic control amounts to "the virtual governance of the unlived" (p. 165) and "can never be lived despite orchestrating the present preemptively as present-futurity through the ingression of real potentialities in occasions of experiences" (p. 175). Mnemonic control exploits senses or prehensions of time that feel familiar even though it has not been consciously experienced nor represented within LAP archives. In its control of the unlived, mnemonic control preempts anticipations of a "past not lived, a future not sensed" (Parisi \& Goodman, 2011, p. 164).

The archive of educational memories produced through these learning platforms can also be combined with global data infrastructures to produce additional memories of school and university rankings, and other biopolitical data in order to anticipate prospective employment opportunities (e.g., race and gender). Global data infrastructures in education continually produce information archives that are used to anticipate educational subjects and their employment possibilities, while surreptitiously seducing subjects to prosume these very futures. The data command, which is what subjects remember, and in turn, these memories enact tomorrow's educational habits (e.g., enact repeating circuits of thought and thinking).

Third synthesis of time 
The third synthesis of time is concerned with conditions that produce futures (or the 'new'). Futures, however, are a temporal paradox for Deleuze (1994) because habit and memory constantly reproduce temporalities through passive cycles. There is nothing 'new' or futural within the durational cycles of habits and memory. In other words, the future only reproduces and reinforces path dependencies which entrench existing habits and memories.

For Deleuze, only something that is 'new' could be considered futural, whereas traditional usages of 'future' are only repetitions of the past. Smith $(2013, \mathrm{np})$ is helpful here, when he asks whether it is "... paradoxical to search for the conditions of the new, since the conditioned (the new) would be determined by its conditions, and thus would not be truly new, like an effect that is already contained in its cause? The answer is yes...”. For our purposes, anticipatory governance in education does not proffer anything new, even if it promises a 'future'. The futures of anticipatory governance are determined by its conditions and simply repeat existing habits and memories. Thompson and Cook (2014) explain that educational habits and memory "are synthesis of capture, in that the new is not possible within a colonising lived present in the case of the first synthesis, and a repetitive process of a pure past [second synthesis] that holds no way out from those subjects and objects repetitively created" (p. 707). Here, anticipatory governance automates and accelerates the colonization of educational habits and memories.

The 'new' (or Deleuzian future) is only produced through an active break or rupture of habit and memory. Smith (2013) noted that "Deleuze proposed replacing the possible-real couple with the virtualactual relation: whereas the real resembles the possible, and the actual differs from the virtual. Time, for Deleuze, does not move from one actual term to another, but from the virtual to the actual ...” (np).

With regard to resetting habits and memories, Voss (2013) argued that Deleuze's third synthesis of time "introduces a cut or caesura into consciousness and produces the system of a dissolved self" (p. 
212). The rupture of educational habits and memories is an attempt to break with the chronologies that educational subjects inhabit, and through which they understand themselves. For instance, Bignall (2010) discussed the rupture of temporal habits similarly:

The third synthesis of time involves the thought of time as 'untimely'; it institutes a 'caesura' in the time of the present (Deleuze 1994: 88-9), with respect to the pure past that grounds it, in order to imagine a future which has not yet come to pass, and which imaginatively 'draws a difference' from the present. (p. 16)

The third synthesis of time demands a cut in order for something new to be produced, and in order for the past to not be repeated.

While talk of resetting habits and memories may seem daunting, Bignall (2010) provided a reasonable example of rupturing past habits and memories. She stated, "[f]or example, I could ask of myself: is my habitual form partly comprised of some associations that I would be better off without (a draining colleague, an odious relative)?" (p. 16). The ability to anticipate something other than what is possible is another way of discussing virtuality or the virtual, but what is also being regulated through practices of mnemonic control in education (Parisi and Goodman, 2011). Voss (2013) concluded that habitual and mnemonic ruptures carry "the ungrounded and abandoned subject to a point of metamorphosis, when all its possibilities of becoming are set free. It liberates the subject ... from the rule of identity and law" (p. 207). In other words,

The third synthesis of time thereby involves thinking the actual lived present in terms of its repetitions and its habitual consistencies through time, and asking whether, if the partrelations that comprise actual complex bodies (the 'little selves' that exist 'underneath' the 'self that acts') were returned back to the virtual chaos from whence they came, they would be worthy of returning in the same form. (Bignall, 2010, p. 16) 
We use the idea of the virtual-actual relation as the basis for resetting time in education, and discuss this in our conclusion next.

\section{Forget Education}

Education policy has always had an intimate relationship with the future, promising preparation for a complicated tomorrow. But what if tomorrow never arrives? What if education is a temporal dispositif that repeats the past (Ball, 1995)? The rise of anticipation and prediction is a defining moment in the history of education governance. This fin de siècle has arrived as a result of educational traditions that proffer more hopeful futures, often bogged down by attempts to actualize such futures. In other words, education has maintained that possible futures are knowable, even if the certainty about such conditions remain elusive. Nevertheless, the habits that profess uncertainty about educational futures rarely question that tomorrow can be anticipated.

We have argued that education governance automates control of habits and memories, and to note what kinds of ruptures or breaks from educational policy-making can be developed. Specifically, we suggest that educational habits and memories directed to human capital development and biopolitical reproduction can be ruptured. Rabinow (2008) argued similarly when he stated,

...the diacritic best suited to distinguish modernity as an epoch is the one that marks a temporal break with the past. Making a distinction identifies a rupture-it shows us where to look to see that which is taken to be the crucial dimension of the world that, as long as one accepts this particular distinction, has changed forever. (p. 63)

Education routinely equivocates on its relationships to tomorrow. In other words, education has always preferred futures generated from possible-real relationships and ignored or disparaged futures generated from relationships of virtual-actual. This is why education is always attempting to 'reform' or 'improve' itself; reform efforts are the habitual attempts to improve upon its failed memories of a glorious future. 
Educational governance has illustrated that the anticipatory habits involved in governing others' memories are designed to produce human capital that has been established in a capitalist past for financialized futures (Robertson, 2016). It routinely does so unequally (Brown, 2015). Is it possible to generate anything 'new' in education? Or, is education simply a repetition of the same, marketed as 'the future' or sold as 'the new'?

A third conception of time, kairos, encourages us to become attuned to the potentiality of the present anticipatory moment. Derrida (2006) invoked kairos in his discussion of how Marx's ideas haunt the present, or 'now-time', sustaining contingency and, with careful selection, conditions for the rupture of habitually repeated pasts. Importantly, we believe that the introduction of new AI technologies can contribute to a rupture in educational governance. So much nervous energy and research funding is currently being expended in the effort to 'humanise' AI via attempts to eradicate bias and focus on ideas like 'explainable AI' (Cf., Edwards, 2018). Attempts to humanize AI operate on the premise that AI is not already part of posthuman education policy and governance (Hayles, 1999; 2014). But this humanization is simply another form of control - it is the premise of the anticipatory governance projects to manage emergence in ways deemed congruent with the values of today.

\section{Accelerate anticipation: Letting go of education}

We suggest that education ought to proliferate modes of uncertainty that inhere within in anticipatory governance, specifically as injunctions or ruptures to the habitual mnemonic control in education. For instance, anticipatory governance uses and develops epistemes concerned with likelihoods, probable forecasts, and predictive models and is "redirected as an injunction to characterize and inhabit degrees and kinds of uncertainty" (Adams et al., 2009: 247). Can we let AI infer 'the new' or the virtual, contra to ubiquitous moral calls to regulate AI or develop 'ethics in AI' that simply reinstate old regimes of the 
possible-real? Can we accelerate AI to produce the virtual in order to rupture the habits and memories of education?

Accelerationism describes the view that economic growth drives technological development and vice versa, establishing positive feedback loops that compress the time of production (Land, 2014). While some accelerationists advocate for managing this process or pushing it to its limits, others argue that this dynamic is not susceptible to human regulation. Unconditional accelerationists answer the question of what is to be done about technological change by proposing that we let go of our assumption that something can and should be done (Garton, 2017). From this perspective, the problem of managing techno-economic systems is reframed as a problem of desire for such control, or the repetition of habit and memory. How far can we go in letting go of this desire? This letting go involves a deterritorialization of desire, and then of compensatory reterritorializations. Of course, this may appear to be the worst kind of passive nihilism, but from another perspective it can be seen as the process through which desire and habit are reset.

The educational task today is to accelerate LAP simulations, for example, in ways that rupture educational habits and memories, rather than to discard algorithmic outputs as 'improbable' or 'not possible'. In other words, what other habits and memories might AI calculate besides those already programmed to develop human capital? The probabilities, uncertainties, and speculative forecasts of new algorithimic rationalities, which identify the virtual, open possibilities in the present that do not depend on human agency or deliberative politics. The opportunity of the present moment may be to let go of the desire for control that underpins the policy sciences designed for human capital development, rather than to pursue control of a different kind.

We acknowledge that the resetting of habits and memories is likely too arduous a task. We also acknowledge the ambivalence and antipraxis of accelerationism. Another kaironic or untimely moment 
to anticipatory governance in education might be one in which to maneuver in education as “incomputable" (Majaca \& Parisi, 2016) or as “imperceptible” (Grosz, 2002). Becoming-incomputable or becoming-imperceptible provides an untimely politics that accepts that education futures "operate with machines ... whose passive danger is jamming and whose active one is piracy and the introduction of viruses" (Deleuze, 1992, p. 6). There may be time in education to engage in a 'politics of hacking' as anticipations of educational futures become increasingly predicted. But then that time is always now. 


\section{References}

Adams, V., Murphy, M., \& Clarke, A. E. (2009). Anticipation: Technoscience, life, affect, temporality. Subjectivity, 28(1), 246-265.

Aulck, L., Velagapudi, N., Blumenstock, J., and West, J. (2017). Predicting student dropout in higher education. https://arxiv.org/pdf/1606.06364.pdf

Ball, S. J. (1995). Intellectuals or technicians? The urgent role of theory in education studies. British Journal of Educational Studies, 43, 255-271.

Becker, G. S. (1963). Human capital: A theoretical and empirical analysis, with special reference to education. The University of Chicago Press.

Bennett, A., \& Burke, P. J. (2018). Re/conceptualising time and temporality: an exploration of time in higher education. Discourse: Studies in the Cultural Politics of Education, 39(6), 913-925.

Bergson, H. (2001). Time and free will: An essay on the immediate data of consciousness. Mineola, NY: Dover Publications.

Berlant, L. (2011). Cruel optimism. Durham, NC: Duke University Press.

Bignall, S. (2010). Desire, apathy and activism. Deleuze Studies, 4, 7-27.

Brown, W. (2015). Undoing the demos: Neoliberalism's stealth revolution. Brooklyn: NY: Zone Books.

Brown, W. (2005). Edgework: Critical essays on knowledge and politics. Princeton University Press.

de Freitas, E. (2018). The biosocial subject: sensor technologies and worldly sensibility. Discourse: Studies in the Cultural Politics of Education, 39(2), 292-308.

Deleuze, G. (1991). Empiricism and subjectivity: An essay on Hume’s theory of human nature. Columbia University Press.

Deleuze, G. (1992). Postscript on the societies of control. October 59(Winter), 3-7.

Deleuze, G. (1994). Difference and repetition. New York, NY: Columbia University Press. 
Deleuze, G., \& Guattari, F. (1983). Anti-Oedipus. Minneapolis: University of Minnesotta Press.

Derrida, J., Kamuf, P., Magnus, B., \& Cullenberg, S. (n.d.). Specters of Marx: The state of debt, the work of mourning and the new international.

Edwards, P. N. (2018). We have been assimilated: Some principles for thinking about algorithmic systems. https://doi.org/10.1007/978-3-030-04091-8_3

Fenwick, T., Mangez, E., Ozga, J. (2014). Governing knowledge: Comparison, knowledge-based technologies and expertise in the regulation of education. New York, NY: Routledge.

Foucault, M., Senellart, M., Burchell, G., Collège de France., \& College de France. (2008). The birth of biopolitics: Lectures at the Collège de France, 1978-79. Palgrave Macmillan.

Garton, V. (2017). Unconditional accelerationism as antipraxis. Blog post. https://cyclonotrope.wordpress.com/2017/06/12/unconditional-accelerationism-as-antipraxis/

Gibson, D. and de Freitas, S. (2016). Exploratory analysis in learning analytics. Technology, knowledge and learning. 21(5), 5-19.

Grosz, E. (2002). A politics of imperceptibility. Philosophy and Social Criticism, 28(4), 463-472.

Gulson, K. N. and Sellar, S. (2018). Emerging data infrastructures and the new topologies of education policy. Environment and Planning D: Society and Space, 37(2), 350-366.

Gulson, K. N. and Webb, P. T. (2017a). Mapping an emergent field of 'computational education policy': Policy rationalities, prediction and data in the age of Artificial Intelligence. Research in Education, 98(1), 14-26.

Gulson, K. N. \& Webb, P. T. (2017b). Emerging biological rationalities for policy: (Molecular) biopolitics and the new authorities in education. In S. Parker, T. Gale and K. Gulson (Eds.), Education Policy and Social Inequality: Policy and Inequality in Education (pp. 23-40). Singapore: Springer. 
Hartong, S. (2019). Personal communication.

Hayles, K. (1999). How we became posthuman: Virtual bodies in cybernetics, literature, and informatics. Chicago, IL: The University of Chicago Press.

Hayles, N. K. (2014). Cognition everywhere: The rise of the cognitive nonconscious and the costs of consciousness. New Literary History, 45(2), 199-220.

Land, N. (2014). Teleoplexy: Notes on acceleration. In R. Mackay \& A. Avanessian (Eds.), \#Accelerate\#: The Accelerationist Reader (pp. 509-520). Falmouth: Urbanomic.

Lerner, D., \& Laswell, H. D. (1951). The policy sciences: Recent developments in scope and method. Palo Alto, CA: Stanford University Press.

Lingard, B., \& Thompson, G. (2017). Doing time in the sociology of education. British Journal of Sociology of Education, 38(1), 1-12.

Luckin, R., Holmes, W., Griffiths, M., \& Forcier, L. B. (2016). Intelligence unleashed: An argument for AI in Education. London: Pearson.

Majaca, A. And Parisi, L. (2016). The incomputable and instrumental possibility. e-flux, 77(November), http://worker01.e-flux.com/pdf/article_76322.pdf.

Marx, K. (1863). Letter to Engels. https://marxists.catbull.com/archive/marx/works/1863/letters/63_01_28.htm

Papastephanou, M. (n.d.). Higher education and an ethic of time. In P. Gibbs, O.-H. Ylijoki, C. GuzmánValenzuela, \& R. Barnett (Eds.), Universities in the flux of time: An exploration of time and temporality in university life (pp. 168-181). New York, NY: Routledge.

Parisi, L. (2019). Critical Computation: Digital Automata and General Artificial Thinking. Theory, Culture \& Society. https://doi.org/10.1177/0263276418818889

Parisi, L. (2013). Contagious architecture: Computation, aesthetics, and space. MIT Press. 
Parisi, L. and Goodman, S. (2011) 2011. Mnemonic control. In P. T. Clough and C. Willse (Eds.), Beyond biopolitics: Essays on the governance of life and death (pp. 163-176). Durham. NC: Duke University Press.

Parsons, W. (1995). Public policy: An introduction to the theory and practice of policy analysis. Cheltenham: Edward Elgar.

Piotrowski, M. (2019). Subjectivity in the folds: Education, media practices, and environmental activism amongst more-than-human pleats. Unpublished doctoral dissertation. http://hdl.handle.net/2429/71050.

Rabinow, P. (2008). Marking time. Princeton, NJ: Princeton University Press.

Robertson, S. (2016). Piketty, capital and education: A solution to, or problem in, rising social inequalities? British Journal of Sociology of Education, 37(6), 823-835.

Rose, N. (2001). The politics of life itself. Theory, Culture \& Society, 18(6), 1-30.

Rose, N. S., \& Abi-Rached, J. M. (2013). Neuro: The new brain sciences and the management of the mind. Princeton University Press.

Scott, D. (2005). Critical realism and empirical research methods in education. Journal of Philosophy of Education, 39(4), 633-646.

Sellar, S. and Zipin, L. (2018): Conjuring optimism in dark times: Education, affect and human capital. Educational Philosophy and Theory, 51(6), 572-586.

Sellar, S. and Thompson, G. (2016). The becoming-statistic: Information ontologies and computerized adaptive testing in education. Cultural Studies $<>$ Critical Methodologies, 16(5), 491-501.

Selwyn, N. (2015). Data entry: Towards the critical study of digital data and education. Learning, Media and Technology, 40(1), 64-82. 
Stendera, M. (2015). Being-in-the-world, temporality and autopoiesis. Parrhesia: A journal of critical philosophy, 24, 261-284.

Simons, M., Olssen, M., \& Peters, M. A. (2009). Re-reading education policies: A handbook studying the policy agenda of the 21st century. Rotterdam: Sense Publishers.

Stiegler, B. (2016). Automatic society: The future of work. Malden, MA: Polity Press.

Thompson, G., \& Cook, I. (2014). Education policy-making and time. Journal of Education Policy, 29(5), 700-715.

Thompson, G., \& Cook, I. (2017). The logic of data-sense: thinking through Learning Personalisation. Discourse: Studies in the Cultural Politics of Education, 38(5), 740-754.

Voss, D. (2013). Deleuze's third synthesis of time. Deleuze Studies, 7(2), 194-216.

Whitehead, A. N. (1978). Process and reality. New York: Simon and Schuster.

Webb, P. T. and Gulson, K. (2015). Policy, geophilosophy and education. Netherlands: Sense Publishers.

Webb, P. T. and Gulson, K. (2013). Policy intensions and the folds of the self. Educational Theory, 63(1), 51-68.

Webb, P. T. and Gulson, K. (2012). Policy prolepsis in education: Encounters, becomings, and phantasms. Discourse: Studies in the Cultural Politics of Education, 33(1), 87-99.

West, D., Heath, D. and Huijser, H. (2016). Let's talk learning analytics: A framework for implementation in relation to student retention. Journal of Asynchronous Learning Network, 20(2).

Williams, J. (2011). Gilles Deleuze's philosophy of time: A critical introduction and guide. Retrieved from https://ndpr.nd.edu/news/gilles-deleuze-s-philosophy-of-time-a-critical-introduction-andguide/ 
Williamson, B. (2016a). Coding the biodigital child: the biopolitics and pedagogic strategies of educational data science. Pedagogy, Culture \& Society, 24(3), 401-416.

Williamson, B. (2016b). Digital education governance: data visualization, predictive analytics, and 'realtime’ policy instruments. Journal of Education Policy, 31(2), 123-141.

Wilsdon, J. (2014). From foresight to hindsight: The promise of history in responsible innovation. Journal of Responsible Innovation, 1(1), 109-112. 